\title{
Evaluation of Phosphate Solubilisation Potential of Eight Isolate of Aspergillus niger and their Utility in Enhancing the Growth of Piper longum under Field Condition
}

\author{
Hruda Ranjan Sahoo* and Nibha Gupta
}

Division of Plant Pathology and Microbiology, Regional Plant Resource Centre, Bhubaneswar-751015, Odisha, India

*Corresponding author

\begin{tabular}{l} 
K e y w o r d s \\
$\begin{array}{l}\text { Aspergillus niger, Piper } \\
\text { longum, P solubilisation } \\
\text { potential, Growth } \\
\text { parameters, Plant- } \\
\text { microbe interaction }\end{array}$ \\
\hline Article Info \\
\hline $\begin{array}{l}\text { Accepted: } \\
\text { 23 March } 2018 \\
\text { Available Online: } \\
\text { 10 April } 2018\end{array}$ \\
\hline
\end{tabular}

A B S T R A C T

\begin{abstract}
Experimentation with inoculation of 8 different strains of Aspergillus niger with $\mathrm{P}$ solubilisation potential into plants of Piper longum showed drastic variation in growth parameters and development pattern as compared to control plants which is quite evident from the values obtained during the growth period. Aspergillus niger strain 1 inoculated plants showed maximum branching (13.25 \pm 2.65$)$ as compared to control showing $(8.4 \pm 2.77)$ and also showed highest leaf development with number of leaves $(40.75 \pm 3.59)$ whereas control plants showed only $(27.63 \pm 9.43)$ number of leaves. On the other hand, the plant height was higher in Aspergillus niger strain 7 treated plants showing $(94.5 \pm 31.03)$ $\mathrm{cm}$ when compared to control plants with $(57.4 \pm 16.3) \mathrm{cm}$ and increase in root length was $(35 \pm 9.2) \mathrm{cm}$ in Aspergillus niger strain 2 which is almost double length of control plants $(17.5 \pm 3.53) \mathrm{cm}$ along with leaf area which is recorded to be $(519.4 \pm 46.8) \mathrm{cm}^{2}$. Most of $A$. niger strains improved plant growth suggesting that $\mathrm{P}$ solubilising strains help in $\mathrm{P}$ uptake in plants. Both the strains Aspergillus niger strain 2 and 8 influenced the fresh and dry leaf biomass of the plant. Maximum fruit development was observed in Aspergillus niger strain 5 (7 in 120 days, 14 in 150 days and 32 in 180 days, respectively. Again, maximum Leaf Area Ratio (LAR) is observed in plants inoculated with Aspergillus niger strain 2 having $699.1 \mathrm{~cm} 2 / \mathrm{g}$ but maximum Relative Growth Rate (RGR) of $10.45 \mathrm{mg} / \mathrm{g} /$ day and Net Assimilation Rate (NAR) of $1.63 \mathrm{~g} / \mathrm{cm} 2 /$ day was obtained in plants inoculated with Aspergillus niger strain 4. From the above findings, it is clear that specific strains impart growth as well as development of the plant which needs an elaborate study to confirm the mode of plant-microbe interaction.
\end{abstract}

\section{Introduction}

Plant growth and development is also related to its access to minerals such as phosphorus. Phosphorus is second most important mineral macronutrient in the plant system after nitrogen (Donahue et al., 1990). It is key constituent of cellular molecules, such as phospholipids, nucleic acids and nucleotides but it exists in nature in the form of insoluble organic and inorganic forms. $\mathrm{P}$ content in soil becomes deficient due to fixation into bound $\mathrm{P}$ restricts proper growth of plants. This nutrient is acquired by plants from the soil solution 
mainly in the form of $\mathrm{H}_{2} \mathrm{PO}_{4}{ }^{-}$and $\mathrm{HPO}_{4}{ }^{2-}$ but only minute amount is available for plant absorption because of insoluble form. Indeed, research in this area is becoming critical because majority of $\mathrm{P}$ fertilisers are obtained from phosphate rock, a non-renewable source of $\mathrm{P}$ that is expected to be exhausted in 30 to 50 years and because the exploited deposits are of increasingly lower quality, which results in increases in the cost of phosphate fertiliser production. Moreover, soluble chemical fertilizers are quickly immobilized in the soil, and thus not available for plant growth. So, Alternative and cleaner agricultural practices have to be developed. The present trend is directed towards increasing the availability of native soil phosphorus which can be achieved by inoculating the effective microbes in the rhizosphere. Natural solubilisation of mineral phosphates is a characteristic exhibited by most of the phosphate solubilising microbes by mobilising the insoluble inorganic phosphates so that they can be absorbed by plant roots (Perez et al., 2007). These Phosphate solubilising microorganisms could supply phosphate to the plants in a more environmentally friendly manner. Moreover, use of these beneficial microbes as bioinoculants would reduce the cost of chemical fertilizers as well. Most of the tropical soils are phosphorus fixing hence free form of phosphate is not available to the plants. Application of mineral solubilisers to such type of problematic soils could be an effective method to achieve higher growth and productivity of economic importance. Hence, PSM can be used for biofertilization to improve crop yield (Khan et al., 2007; Sharma et al., 2012; Onyia and Anyanwu, 2013). Many investigators have reported growth promotion and increased yield in crop plants such as cucumber, lettuce, tomato etc. inoculated with $\mathrm{P}$ solubilising fungi (Morales et al., 2011; Sibi, 2011; Anwer and Khan, 2013; Islam et al., 2014). Soil inoculation with phosphate solubilising microbes improves solubilization of fixed soil $\mathrm{P}$ and applied phosphates so that $\mathrm{P}$ is available to the plant for growth and development. This requires selection of the most appropriate strains, preparation of effective formulation and introduction of inoculants for improving $\mathrm{P}$ efficiency. Aspergillus niger isolated from soil is reported to solubilize inorganic phosphorus by various authors (Kang et al., 2008; Zeroul et al., 2012; Singh et al., 2012). Endophytic microbes associated with plant are also known to promote its growth and increases productivity due to their capacity of solubilising $\mathrm{P}$ mostly $\mathrm{Ca}$ and $\mathrm{Fe}$ phosphates (Vitrino et al., 2012).

Piper longum is a slender aromatic climber having several medicinal properties due to the dry spikes of female types which is economically important. This is the reason for its over exploitation and more than 100 Metric tonnes/year of dry weight of long pepper is being traded. As a result of which it is disappearing rapidly. Therefore, large scale cultivation should be promoted to enhance its population in the wild. Due to several problems such as lack of quality planting material, mortality in field and poor growth associated with large scale cultivation. Though growth enhancement of many agricultural and horticultural crops by application of fungal strains has been reported by several authors but very little is known about their potential to enhance the productivity of Medicinal plants belonging to the genus Piper and such information on Piper longum is not available till date. However, the effect of inoculation with four native Arbuscular mycorrhizal fungi (AMF), Glomus mosseae, Glomus fasciculatum, Glomus clarum and Glomus versiforme on growth performance of medicinal plant "Long pepper" (Piper longum L.) was studied by Singh and Gogoi (2010). Even several reports are available on the antibacterial activity, antiallergic activity, 
antigiardial activity and antitumor activity of Piper longum (Reddy et al., 2001; Amit et al., 2003; Sunila and Kuttan, 2004) but studies on its association with different microbes or dependency on microbes for better growth and productivity still demand a systematic and detailed approach. The present study emphasizes on the application of isolates of Aspergillus niger from endophytic sources with efficient $\mathrm{P}$ solubilising capacity as biofertilization in order to enhance the growth and productivity of Piper longum which is one of the endangered plant species in Odisha state.

\section{Materials and Methods}

The phosphate solubilising fungal strains of Aspergillus used in pot experiment were identified based on their plate culture on different media, slide culture and sporulation pattern through microscopic studies. Phosphate solubilising fungi were used for inoculation studies along with uninoculated control soil. The pot experiment was conducted in polypots under greenhouse conditions in the nursery of Regional Plant Resource Centre, Bhubaneswar.

The black polypots of 10 "x 10 " size with $5 \mathrm{~kg}$ capacity filled with red laterite soil was used. The soil used for the experiment was acidic with $\mathrm{pH} 6.06$, electrical conductivity $0.2 \mathrm{dSm}$ 1 , Organic carbon $0.9 \%$, available $\mathrm{N}, \mathrm{P}, \mathrm{K}$ as 232, 25 and $99 \mathrm{~kg} / \mathrm{ha}$ respectively, $\mathrm{Ca}$ and $\mathrm{Na}$ with 6.6 and $0.174 \mathrm{meq} / 100 \mathrm{~g}$ respectively. However the concentration of micronutrients such as $\mathrm{Fe}, \mathrm{Mn}, \mathrm{Cu}$ and $\mathrm{Zn}$ includes 32, 11, 1 and $0.3 \mathrm{mg} / \mathrm{kg}-1$ respectively. All the polypots of $5 \mathrm{~kg}$ capacity were filled with sterile soil before transplanting the rooted stem cuttings of Piper longum plant. This was done in 10 replications for each treatment. The experiment was done in completely randomized block design with treatments in replications. The pots were inoculated with fungal cultures at regular intervals and were maintained in the green house at an adequate temperature with daily water supply to maintain the soil moisture level and without any application of fertilizer. The plant growth parameters especially observation of morphological details was done.

The parameters such as leaf number, branch number, shoot height and fresh weight, root length and fresh weight, leaf area and fresh weight were recorded periodically. Dry weight of plant biomass such as shoot, root and leaf samples were determined after drying at $60^{\circ} \mathrm{C}$ in the hot air oven for 48 hours. The observations recorded after 30,60 and 90 days were compared with the control setup. The RGR, NAR and LAR were also calculated for all the treatments. Fruiting was observed after 120 days of fungal inoculation into the plants. The male and female spike development, their maturation and spike length was also recorded after 150 and 180 days.

\section{Results and Discussion}

Inoculation of different strains of Aspergillus niger with $\mathrm{P}$ solubilisation potential into plants of Piper longum showed variation in growth parameters as compared to control. Aspergillus niger strain 1 inoculated plants showed maximum branching (13.25 \pm 2.65$)$ as compared to control showing (8.4 \pm 2.77$)$. However, Aspergillus niger strain 5 also showed good branching (11.75 \pm 3.3$)$. Aspergillus niger strain 1 also showed highest leaf development with number of leaves $(40.75 \pm 3.59)$ whereas control plants showed only (27.63 \pm 9.43$)$ number of leaves. Aspergillus niger strain 7 showed leaf number as (40.25 \pm 6.4$)$ and maximum plant growth $(94.5 \pm 31.03) \mathrm{cm}$ after 120 days of inoculation. The plant height was also higher in Aspergillus niger strain 2 treated plants showing $(89.8 \pm 25.81) \mathrm{cm}$. The shoot height in control plants was found to be $(57.4 \pm 16.3) \mathrm{cm}$. (Table 1-4) 
Table.1 Growth parameters recorded for Piper longum after regular interval inoculated with different strains of Aspergillus niger

A) 30 days

\begin{tabular}{|c|c|c|c|c|c|c|c|c|c|c|c|}
\hline & & & & SHOOT & & & ROOT & & & LEAF & \\
\hline TREATMENT & $\begin{array}{l}\text { No. of } \\
\text { branches }\end{array}$ & $\begin{array}{l}\text { No. of } \\
\text { leaves }\end{array}$ & height & fresh weight & dry weight & length & fresh weight & dry weight & area & fresh weight & Dry weight \\
\hline Control & $5.5 \pm 0.71$ & $\begin{array}{c}7 \pm \\
1.41\end{array}$ & $\begin{array}{l}36.5 \pm \\
12.02\end{array}$ & $2.133 \pm 0.89$ & $\begin{array}{l}0.27 \pm \\
0.115\end{array}$ & $9.25 \pm 0.35$ & $\begin{array}{c}1.01 \pm \\
0.13\end{array}$ & $0.138 \pm 0.018$ & $261.63 \pm 23.16$ & $3.615 \pm 0.61$ & $0.497 \pm 0.038$ \\
\hline F2 & $5 \pm 0$ & $6 \pm 0$ & $38 \pm 8.49$ & $2.235 \pm 1.26$ & $0.26 \pm 0.21$ & $18.25 \pm 1.77$ & $0.91 \pm 0.35$ & $0.142 \pm 0.08$ & $288 \pm 44.55$ & $3.67 \pm 1.49$ & $0.499 \pm 0.064$ \\
\hline F3 & $5.5 \pm 0.71$ & $6.5 \pm 0.71$ & $52.5 \pm 14.14$ & $2.23 \pm 0.95$ & $0.28 \pm 0.007$ & $22.25 \pm 3.89$ & $0.67 \pm 0.04$ & $0.165 \pm 0.02$ & $390.625 \pm 31.64$ & $2.88 \pm 0.27$ & $0.439 \pm 0.016$ \\
\hline F4 & $4.5 \pm 2.12$ & $5.5 \pm 2.12$ & $28.75 \pm 15.9$ & $1.74 \pm 0.35$ & $0.206 \pm 0.116$ & $15.6 \pm 5.09$ & $1.01 \pm 0.64$ & $0.120 \pm 0.077$ & $228.95 \pm 113.07$ & $2.174 \pm 1.24$ & $0.308 \pm 0.18$ \\
\hline F5 & $6.5 \pm 2.12$ & $7.5 \pm 2.12$ & $65.25 \pm 32.17$ & $2.71 \pm 1.69$ & $0.304 \pm 0.23$ & $15.75 \pm 1.77$ & $1.08 \pm 0.545$ & $0.131 \pm 0.049$ & $333.18 \pm 109.5$ & $3.12 \pm 0.92$ & $0.441 \pm 0.085$ \\
\hline F6 & $5.5 \pm 0.71$ & $6.5 \pm 0.71$ & $50.75 \pm 16.6$ & $2.47 \pm 1.25$ & $0.4 \pm 0.247$ & $15 \pm 1.414$ & $1.086 \pm 0.49$ & $0.187 \pm 0.074$ & $225.38 \pm 74.78$ & $3.48 \pm 1.86$ & $0.547 \pm 0.28$ \\
\hline F7 & $6 \pm 1.41$ & $7 \pm 1.41$ & $41.75 \pm 2.47$ & $1.41 \pm 0.079$ & $0.216 \pm 0.028$ & $21 \pm 3.54$ & $0.672 \pm 0.028$ & $0.127 \pm 0.013$ & $175.38 \pm 3.36$ & $2.302 \pm 0.43$ & $0.289 \pm 0.05$ \\
\hline F9 & $6 \pm 1.41$ & $7 \pm 1.41$ & $47.9 \pm 25.6$ & $1.77 \pm 0.96$ & $0.217 \pm 0.102$ & $16.45 \pm 1.34$ & $0.67 \pm 0.19$ & $0.061 \pm 0.016$ & $357.75 \pm 138.94$ & $3.04 \pm 0.62$ & $0.47 \pm 0.13$ \\
\hline F10 & $5.5 \pm 0.71$ & $7 \pm 0$ & $37.5 \pm 2.12$ & $1.361 \pm 0.008$ & $0.176 \pm 0.003$ & $15.25 \pm 7.42$ & $0.619 \pm 0.049$ & $0.065 \pm 0.005$ & $226.65 \pm 2.47$ & $3.315 \pm 0.17$ & $0.528 \pm 0.059$ \\
\hline
\end{tabular}

B) 60 days

\begin{tabular}{|c|c|c|c|c|c|c|c|c|c|c|c|}
\hline & & & & SHOOT & & & ROOT & & & LEAF & \\
\hline TREATMEN' & $\begin{array}{l}\text { No. of } \\
\text { branches }\end{array}$ & $\begin{array}{l}\text { No. of } \\
\text { leaves }\end{array}$ & height & fresh weight & dry weight & length & fresh weight & dry weight & area & fresh weight & dry weight \\
\hline control & $5 \pm 2.83$ & $4 \pm 2.83$ & $43.45 \pm 3.18$ & $2.857 \pm 0.62$ & $0.343 \pm 0.15$ & $9 \pm 1.41$ & $1.15 \pm 0.5$ & $0.317 \pm 0.14$ & $253 \pm 171$ & $2.775 \pm 1.3$ & $0.44 \pm 0.23$ \\
\hline F2 & $4.5 \pm 0.71$ & $5.5 \pm 0.71$ & $31.4 \pm 11.3$ & $1.64 \pm 0.24$ & $0.267 \pm 0.003$ & $14.25 \pm 0.35$ & $0.795 \pm 0.2$ & $0.188 \pm 0.05$ & $156.5 \pm 47.02$ & $1.907 \pm 0.46$ & $0.367 \pm 0.04$ \\
\hline F3 & $8.5 \pm 0.71$ & $10 \pm 1.41$ & $70 \pm 32.53$ & $4.121 \pm 3.01$ & $0.549 \pm 0.46$ & $21.5 \pm 14.8$ & $0.916 \pm 0.69$ & $0.26 \pm 0.2$ & $393.13 \pm 162.45$ & $4.458 \pm 2.2$ & $0.897 \pm 0.18$ \\
\hline F4 & $5.5 \pm 0.71$ & $7 \pm 1.41$ & $36 \pm 4.24$ & $1.854 \pm 0.1$ & $0.35 \pm 0.03$ & $16 \pm 8.5$ & $0.921 \pm 0.67$ & $0.257 \pm 0.19$ & $221.88 \pm 53.9$ & $2.39 \pm 0.07$ & $0.547 \pm 0.04$ \\
\hline F5 & $6.5 \pm 0.71$ & $8.5 \pm 0.71$ & $57.8 \pm 2.55$ & $3.07 \pm 0.2$ & $0.418 \pm 0.03$ & $10 \pm 1.41$ & $0.671 \pm 0.18$ & $0.253 \pm 0.07$ & $369.13 \pm 27.8$ & $4.268 \pm 0.71$ & $0.714 \pm 0.09$ \\
\hline F6 & $7 \pm 0$ & $8.5 \pm 0.71$ & $60.75 \pm 1.77$ & $2.917 \pm 1.09$ & $0.397 \pm 0.15$ & $15.75 \pm 0.35$ & $0.499 \pm 0.16$ & $0.119 \pm 0.04$ & $325.13 \pm 85.7$ & $3.774 \pm 1.28$ & $0.664 \pm 0.19$ \\
\hline F7 & $4 \pm 1.41$ & $6.5 \pm 0.71$ & $44.35 \pm 8.3$ & $2.002 \pm 0.32$ & $0.273 \pm 0.04$ & $11.5 \pm 0.71$ & $0.4 \pm 0.17$ & $0.073 \pm 0.03$ & $195.13 \pm 47.91$ & $2.122 \pm 0.49$ & $0.382 \pm 0.04$ \\
\hline F9 & $7.5 \pm 0.71$ & $8.5 \pm 0.71$ & $50.45 \pm 15.5$ & $2.855 \pm 0.85$ & $0.384 \pm 0.1$ & $13.4 \pm 4.53$ & $0.832 \pm 0.09$ & $0.141 \pm 0.016$ & $348.25 \pm 12.4$ & $4.265 \pm 0.39$ & $0.677 \pm 0.05$ \\
\hline F10 & $10 \pm 1.41$ & $13.5 \pm 0.71$ & $61.8 \pm 3.1$ & $3.9 \pm 0.52$ & $0.544 \pm 0.08$ & $6.85 \pm 0.78$ & $0.631 \pm 0.18$ & $0.144 \pm 0.04$ & $517.63 \pm 119.32$ & $5.388 \pm 0$ & $\begin{array}{l}1.05 \pm \\
0.022\end{array}$ \\
\hline
\end{tabular}


C) 90 days

\begin{tabular}{|c|c|c|c|c|c|c|c|c|c|c|c|}
\hline & & & & SHOOT & & & ROOT & & & LEAF & \\
\hline TREATMENT & $\begin{array}{c}\text { No. of } \\
\text { branches }\end{array}$ & $\begin{array}{c}\text { No. } \\
\text { of leaves }\end{array}$ & height & fresh weight & dry weight & length & fresh weigh & try weight & area & fresh weight & dry \\
\hline control & $6.5 \pm 3.54$ & $8 \pm 4.24$ & $41.25 \pm 5.3$ & $2.672 \pm 0.54$ & $0.43 \pm 0.04$ & $17.5 \pm 3.53$ & $0.47 \pm 0.27$ & $0.101 \pm 0.059$ & $9270.4 \pm 214.4$ & $3.17 \pm 2.32$ & $0.49 \pm 0.32$ \\
\hline F3 & $10 \pm 1.41$ & $13.5 \pm 0.71$ & $89.8 \pm 25.81$ & $4.09 \pm 0.28$ & $0.55 \pm 0.13$ & $35 \pm 9.2$ & $1.42 \pm 0.17$ & $0.325 \pm 0.07$ & $519.4 \pm 46.8$ & $5.66 \pm 0.08$ & $0.99 \pm 0.09$ \\
\hline F4 & $6 \pm 1.41$ & $8 \pm 2.83$ & $43.8 \pm 2.47$ & $1.43 \pm 0.2$ & $0.172 \pm 0.004$ & $24 \pm 1.41$ & $0.363 \pm 0.02$ & $0.11 \pm 0.02$ & $183.75 \pm 42.8$ & $2.06 \pm 0.44$ & $0.31 \pm 0.07$ \\
\hline F7 & $5.5 \pm 0.71$ & $6.5 \pm 0.71$ & $32.6 \pm 1.27$ & $2.29 \pm 1.01$ & $0.30 \pm 0.143$ & $15 \pm 2.12$ & $0.94 \pm 0.8$ & $0.155 \pm 0.11$ & $264.6 \pm 68.8$ & $3.06 \pm 1.04$ & $0.52 \pm 0.19$ \\
\hline F9 & $7 \pm 1.41$ & $8 \pm 1.41$ & $61.4 \pm 1.63$ & $4.52 \pm 0.05$ & $0.49 \pm 0.017$ & $22.25 \pm 1.77$ & $0.66 \pm 0.26$ & $0.18 \pm 0.11$ & $303.8 \pm 35.7$ & $3.95 \pm 0.39$ & $0.60 \pm 0.07$ \\
\hline F10 & $5 \pm 1.41$ & $6 \pm 1.41$ & $37.4 \pm 8.3$ & $2.03 \pm 0.34$ & $0.22 \pm 0.007$ & $21 \pm 2.12$ & $0.92 \pm 0.66$ & $0.17 \pm 0.12$ & $205.9 \pm 24.22$ & $2.59 \pm 0.41$ & $0.33 \pm 0.08$ \\
\hline
\end{tabular}

A) 120 days

\begin{tabular}{|c|l|l|l|l|} 
Treatment & $\begin{array}{l}\text { No. of } \\
\text { leaves }\end{array}$ & $\begin{array}{l}\text { No. of } \\
\text { branches }\end{array}$ & $\begin{array}{l}\text { SHOOT } \\
\text { HEIGHT }\end{array}$ & $\begin{array}{l}\text { No.of } \\
\text { fruit }\end{array}$ \\
\hline Control & $27.63 \pm 9.43$ & $8.4 \pm 2.77$ & $57.4 \pm 16.3$ & $0 \pm 0$ \\
\hline F2 & $40.75 \pm 3.59$ & $13.5 \pm 2.65$ & $86.5 \pm 5.45$ & $1.5 \pm 1.3$ \\
\hline F3 & $34.75 \pm 2.22$ & $8 \pm 1.15$ & $69.75 \pm 20.52$ & $1.5 \pm 1.3$ \\
\hline F4 & $28 \pm 3.46$ & $7.5 \pm 1.3$ & $71.25 \pm 29.95$ & $1 \pm 1.41$ \\
\hline F5 & $34.5 \pm 7.94$ & $11.25 \pm 3.59$ & $73.5 \pm 9.9$ & $0.5 \pm 0.58$ \\
\hline F6 & $35.25 \pm 9.46$ & $11.75 \pm 3.3$ & $65.5 \pm 14.1$ & $1.75 \pm 2.87$ \\
\hline F7 & $26 \pm 11.53$ & $9.3 \pm 3.8$ & $55.7 \pm 24$ & $0 \pm 0$ \\
\hline F9 & $40.25 \pm 6.4$ & $10.5 \pm 1.73$ & $94.5 \pm 31.03$ & $1 \pm 1.15$ \\
\hline F10 & $31.75 \pm 9.25$ & $8.5 \pm 2.9$ & $55.75 \pm 15.3$ & $0 \pm 0$ \\
\hline
\end{tabular}


Table.2 Fruit development recorded in P. longum

\begin{tabular}{|c|c|c|c|}
\hline Treatment & $\mathbf{1 2 0}$ days & $\begin{array}{c}\mathbf{1 5 0} \\
\text { days }\end{array}$ & $\begin{array}{l}\mathbf{1 8 0} \\
\text { days }\end{array}$ \\
\hline Control & 0 & 0 & 0 \\
\hline F2 & 6 & 7 & 11 \\
\hline F3 & 6 & 5 & 4 \\
\hline F4 & 4 & 6 & 12 \\
\hline F5 & 2 & 5 & 12 \\
\hline F6 & 7 & 14 & 32 \\
\hline F7 & 0 & 0 & $\mathbf{0}$ \\
\hline F9 & 4 & 5 & 8 \\
\hline F10 & 0 & 0 & 0 \\
\hline
\end{tabular}

Table.3 Harvesting of spikes of $P$. longum

A) 150 days

\begin{tabular}{c|c|c|c|c|}
\hline $\begin{array}{c}\text { Treatme } \\
\text { nt }\end{array}$ & $\begin{array}{c}\text { Number of male } \\
\text { spike harvested }\end{array}$ & $\begin{array}{c}\text { Number of female } \\
\text { spike harvested }\end{array}$ & $\begin{array}{c}\text { Length of Male } \\
\text { spike (in cm) }\end{array}$ & $\begin{array}{c}\text { Length of female } \\
\text { spike (in cm) }\end{array}$ \\
\hline Control & 0 & 0 & 0 & 0 \\
\hline F2 & 1 & 0 & $6.4 \pm 0$ & 0 \\
\hline F3 & 2 & 1 & $6.3 \pm 0.35$ & $3.3 \pm 0$ \\
\hline F4 & 1 & 0 & $7.7 \pm 0$ & 0 \\
\hline F5 & 0 & 0 & 0 & 0 \\
\hline F6 & 0 & 0 & 0 & 0 \\
\hline F7 & 0 & 0 & 0 & 0 \\
\hline F9 & 2 & 0 & $5.65 \pm 0.21$ & 0 \\
\hline F10 & 0 & 0 & 0 & 0 \\
\hline
\end{tabular}

B) 180 days

\begin{tabular}{|c|c|c|c|c|}
\hline Treatment & $\begin{array}{l}\text { Number of male } \\
\text { spike harvested }\end{array}$ & $\begin{array}{c}\text { Number of female } \\
\text { spike harvested }\end{array}$ & $\begin{array}{l}\text { Length of Male } \\
\text { spike (in cm) }\end{array}$ & $\begin{array}{l}\text { Length of female } \\
\text { spike (in cm) }\end{array}$ \\
\hline Control & 0 & 0 & 0 & 0 \\
\hline F2 & 2 & 0 & $6.25 \pm 0.64$ & 0 \\
\hline F3 & 0 & 0 & 0 & 0 \\
\hline F4 & 3 & 0 & $5.6 \pm 0.82$ & 0 \\
\hline F5 & 1 & 1 & $6 \pm 0$ & $2.8 \pm 0$ \\
\hline F6 & 0 & 9 & 0 & $3.5 \pm 0.55$ \\
\hline F7 & 0 & 0 & - & - \\
\hline F9 & 1 & 0 & $6.7 \pm 0$ & 0 \\
\hline F10 & 0 & 0 & - & - \\
\hline
\end{tabular}


Table.4 Effect on RGR, NAR and LAR

\begin{tabular}{|c|c|c|c|}
\hline Treatment & LAR $(\mathbf{c m} 2 / \mathbf{g})$ & RGR $(\mathbf{m g} / \mathbf{g} / \mathbf{d})$ & NAR $(\mathbf{g} / \mathbf{c m} \mathbf{2} / \mathbf{d})$ \\
\hline Control & 616.25 & 3.25 & 0.68 \\
\hline F2 & 566.4 & 7.2 & 1.08 \\
\hline F3 & 699.1 & 8.02 & 1.12 \\
\hline F4 & 682.3 & 2.83 & 0.18 \\
\hline F5 & 480.7 & 10.45 & 1.63 \\
\hline F6 & 462.24 & 4.6 & 1.2 \\
\hline F7 & 543.7 & 6.68 & 0.9 \\
\hline F9 & 634.2 & 2.87 & 0.2 \\
\hline
\end{tabular}

$\mathrm{F} 2=$ Aspergillus niger strain 1

$\mathrm{F} 3=$ Aspergillus niger strain 2

$\mathrm{F} 4=$ Aspergillus niger strain 3

$\mathrm{F} 5=$ Aspergillus niger strain 4

F6 $=$ Aspergillus niger strain 5

F7 $=$ Aspergillus niger strain 6

F9 $=$ Aspergillus niger strain 7

$\mathrm{F} 10=$ Aspergillus niger strain 8

Most of A. niger strains improved plant growth suggesting that $\mathrm{P}$ solubilising strains help in $\mathrm{P}$ uptake in plants. The increase in root length of $P$. longum plants inoculated with fungal strain Aspergillus niger strain 2 was $(35 \pm 9.2) \mathrm{cm}$ which is almost double length of control plants $(17.5 \pm 3.53) \mathrm{cm}$.

This suggests that the plant roots were able to take up more nutrients. Moreover, the root length of all the treated plants was higher than that of control. Aspergillus niger strain 2 also enhanced leaf area of the plants and after 90 days and it is recorded to be $(519.4 \pm 46.8) \mathrm{cm}^{2}$. Similarly, Aspergillus niger strain 2 also enhanced leaf area to $(519.4 \pm 46.8) \mathrm{cm}^{2}$ which is almost double the area of control plants (270.4 \pm 214.4$) \mathrm{cm}^{2}$.

For plant biomass, it was observed that Aspergillus niger strain 7 showed maximum increase in shoot fresh biomass $(4.52 \pm 0.05) \mathrm{g}$ followed by Aspergillus niger strain 2 showed maximum dry biomass of shoot $(0.55 \pm 0.13) \mathrm{g}$ after 90 days. Similarly, dry weight of shoot in Aspergillus niger strain 7 inoculated plants was also recorded as $(0.49 \pm 0.017) \mathrm{g}$. The root fresh and dry biomass was significantly higher in plants treated with Aspergillus niger strain 4 showing $(1.79 \pm 1.49) \mathrm{g}$ and $(0.57 \pm 0.57) \mathrm{g}$ respectively. Aspergillus niger strain 2 showed higher fresh biomass of leaf $(5.66 \pm 0.08) \mathrm{g}$ followed by Aspergillus niger strain 1 inoculated plants where $(4.08 \pm 2.22) \mathrm{g}$ was recorded. However, the dry leaf biomass was higher in Aspergillus niger strain 2 where $(0.99 \pm 0.09) \mathrm{g}$ biomass was recorded. Hence, both the strains influenced the fresh and dry leaf biomass of the plant.

Maximum fruit development was observed in Aspergillus niger strain 5 (7 in 120 days, 14 in 150 days and 32 in 180 days, respectively) and maximum female spike was also obtained in plants inoculated with same fungi with highest average length of spike being $(3.5 \pm 0.55) \mathrm{cm}$. However, the highest average length of male spike $(7.7 \pm 0) \mathrm{cm}$ was recorded in plants inoculated with Aspergillus niger strain 3 at 150 days. However, no fruit development was observed in control plants and even plants inoculated with Aspergillus niger strain 6 and 8. 
Maximum Leaf Area Ratio (LAR) is observed in plants inoculated with Aspergillus niger strain 2 having $699.1 \mathrm{~cm}^{2} / \mathrm{g}$ but maximum Relative Growth Rate (RGR) of 10.45 $\mathrm{mg} / \mathrm{g} /$ day and Net Assimilation Rate (NAR) of $1.63 \mathrm{~g} / \mathrm{cm}^{2} /$ day was obtained in plants inoculated with Aspergillus niger strain 4. Hence, observations recorded from in depth research done in a systematic approach ascertained with a view that phosphate solubilising microbes are associated with growth and development of Piper longum plant and its valuation is implicated from the pot culture studies conducted with experimental design and analysis made at the end of growth period.

\section{Acknowledgement}

The financial assistance obtained through INSPIRE programme, (No. DST/INSPIRE Fellowship/2013/506) DST, Govt. of India is gratefully acknowledged.

\section{References}

Amit, A., Saxena, V.S., Pratibha, N., D'souza, P., Bagchi, M., Bagchi, D. and Stohs, S.J. 2003. Mast cell stabilization, lipoxygenase inhibition, lyauronidase inhibition, antihistaminic and antispasmodic activities of Aller-7, a novel botanical formulation for Allergic rhinitis. Drugs ExpClin Res, 29(3), 107115 .

Anwer, M.A. and Khan, M.R. 2013.Aspergillus niger as tomato fruit (Lycopersicum esculentum Mill.) quality enhancer and plant health promoter. J Postharvest Technol, 01, $36-51$

Donahue, R.L., Miller, R.W. and Shickluna, J.C. 1990. Soils: An Introduction to Soils and Plant Growth. Prentice Hall of India private Limited, New Delhi, 110001. pp 222-4.
Islam, S., Akanda, A.M., Sultana, F., Hossain, M.M. 2014. Chilli rhizosphere fungus Aspergillus spp. PPA1 promotes vegetative growth of cucumber (Cucumis sativus) plants upon root colonisation. Arch Phytopathol Plant Protect, 47, 1231-1238.

Kang, S.C., Pandey, P., Khillon, R., Maheshwari, D.K. 2008. Process of phosphate solubilization by Aspergillus sp. PS104 in soil amended medium. J Environ Biol, 29,743-746.

Khan, M.S., Zaidi, A., Wani, P.A. 2007. Role of phosphate-solubilizing micro organisms in sustainable agriculture - A review. Agron Sustain Dev, 27, 29-43.

Morales, A., Alvear, M., Valenzuela, E., Castillo, C.E., Borie, F. 2011. Screening, evaluation and selection of phosphate-solubilising fungi as potential biofertilizer. J Soil Sci Plant Nutr, 11, 89-103.

Onyia, C.E., and Anyanwu, CU. 2013. Comparative study on solubilisation of tricalcium phosphate (TCP) by phosphate solubilising fungi isolated from Nsukka pepper plant rhizosphere and root free soil. J yeast fungal Res, 4, 52-57.

Perez, E., Sulbaran, M., Ball, M.M., Yarzabal, L.A. 2007.Isolation and characterization of mineral phosphate solubilising bacteria naturally colonizing a limonitic crust in the south eastern Venezuelan region. Soil biology and Biochemistry, 39, 2905-2914.

Reddy, S.P., Kaiser, J., Madhusudan, P., Anjali, G. and Das, B. 2001. Antibacterial activity of isolates from Piper longum and Taxus baccata. Pharm Biol, 39 (3), 236-38.

Sharma, B.C., Subba, R., Saha, A. 2012. Invitro solubilisation of tricalcium phosphate and production of IAA by phosphate solubilising bacteria isolated 
from tea rhizosphere of Darjeeling, Himalaya. Plant Sci Feed, 2, 96-99.

Sibi, G. 2011. Role of phosphate solubilizing fungi during phosphocompost production and their effect on the growth of tomato (Lycopersicon esculentum L.) plants. J ApplNatlSci, 3 (2), 287-290.

Singh, R., Algh, G.S., Singh, S. 2012. Screening of phosphorus solubilizing Aspergilli from unusual habitats of Agra region. Indian J L Sci, 2,165-168.

Singh, R.K. and Gogoi, P. 2010. Effects of arbuscular mycorrhizal inoculation on growth performance of Piper longum $\mathrm{L}$. (Piperaceae) under sterilized soil condition. Journal of Applied Horticulture, 12(2).
Sunila, E.S. and Kuttan, G. 2004. Immunomodulatory and antitumor activities of Piper longum Linn. and piperine. J Ethanopharmcol, 90 (2-3), 339-346.

Vitorino, L.C., Silva, F.G., Soares, M.A., Souchie, E.L., Costa, A.C., Lima, W.C. 2012. Solubilization of calcium and iron phosphate and in vitro production of Indole acetic acid by endophytic isolates of Hyptis marrubioides Epling (Lamiaceae). Int Res J Biotechnol, 3(4), 47-54.

Zeroual, Y., Chadghan, R., Hakam, A., Kossir, A. 2012.Biosolubilization of mineral insoluble phosphates by immobilized fungi (Aspergillus niger) in fluidized bed bioreactor. J Biotechnol Biomater, 12, 1-5.

\section{How to cite this article:}

Hruda Ranjan Sahoo and Nibha Gupta. 2018. Evaluation of Phosphate Solubilisation Potential of Eight Isolate of Aspergillus niger and their Utility in Enhancing the Growth of Piper longum under Field Condition. Int.J.Curr.Microbiol.App.Sci. 7(04): 2881-2889.

doi: https://doi.org/10.20546/ijcmas.2018.704.328 